\title{
SOBRE A NATUREZA DA INTERROGAÇÃO
}

\author{
Michel Gustavo Fontes
}

\begin{abstract}
RESUMO
Este artigo analisa os diferentes propósitos comunicativos a que se serve o uso das Interrogativas de Conteúdo, comumente denominadas Interrogativas-Q. Com base no modelo da Gramática Discursivo-Funcional, propóe-se que se pense a natureza da interrogação a partir de uma tipologia tripartida: perguntas típicas, retóricas e meditativas.
\end{abstract}

PALAVRAS-CHAVE: Interrogação; Referenciação; Funções interativas e discursivas.

\section{Introdução}

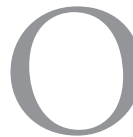

objeto de estudo deste trabalho, as Interrogativas de Conteúdo (comumente denominadas Interrogativas-Q), correspondem a sentenças que contêm um pronome ou advérbio interrogativo, conforme se exemplifica em (1) com dados do NURC.

(1) a. o que a senhora gostaria de fazer? (SP-D2-360)

b. que é que um professor faz...? (SA-DID-231)

c. qual é o problema? (PA-EF-278)

d. quem é que vai comprar? (RJ-EF-379)

e. elas têm origem... onde? (SA-EF-049)

f. quando é que o aluno evidencia conhecimento? (PA-EF-278)

g. quantos o senhor deseja? (RE-EF-337)

h. como que nós chegamos a ela? (SP-EF-405)

i. nao poderia por quê? (RJ-EF-379) 
Segundo Hengeveld e Mackenzie ${ }^{1}$, com uma Ilocução Interrogativa, o Falante requer do Ouvinte uma resposta para o Conteúdo Proposicional evocado pelo Conteúdo Comunicado. Essa resposta pode ser uma confirmação ou não do Ouvinte em relação a um conteúdo cuja verdade não era muito clara para o Falante, o que define uma Interrogativa Polar (cf. (2)), ou pode conter uma informação nova trazida pelo Ouvinte que preencha uma lacuna de informação existente na informação pragmática do Falante, o que define uma Interrogativa de Conteúdo (cf. (3)).

(2) então vocês ahn:: têm irmãos pequenos? (SP-EF-405)

(3) como ela desenha? (SP-EF-405)

A definiçáo acerca de Ilocução Interrogativa proposta por Hengeveld e Mackenzie ${ }^{2}$ corresponde a uma das funçóes discursivas desempenhadas por uma estrutura interrogativa, especificamente a função de pedido de informação, que, segundo Fávero et $a l^{3}$, define-se como "algo que o interlocutor deseja saber por uma questão de necessidade". Entretanto, autores como Lyons ${ }^{4}$ e Vidal ${ }^{5}$ defendem uma multifuncionalidade de usos para as estruturas interrogativas de forma que nem toda interrogativa corresponde a uma estratégia do Falante em solicitar ao Ouvinte uma informação que lhe carece; ao contrário, as razóes que levam um usuário da língua a formular uma estrutura interrogativa são variadas, como manifestar desconhecimento, expressar dúvida, investir numa hipótese, insinuar algo, apresentar um conteúdo polêmico, etc.

1 HENGEVELD, K.; MACKENZIE, L. Functional Discourse Grammar: a typologicallybased theory of language structure. Oxford: Oxford University Press, 2008.

2 HENGEVELD, K.; MACKENZIE, L. Functional Discourse Grammar: a typologicallybased theory of language structure. Oxford: Oxford University Press, 2008.

3 FÁVERO, L. L.; ANDRADE, M. L. C. V. O.; AQUINO, Z. D. O. O par dialógico pergunta-resposta. In: JUBRAN, C. C. S.; KOCH, I. G. V. (Orgs.). Gramática do português culto falado no Brasil: construção do texto falado. V. 1. Campinas: Editora da UNICAMP, 2006. p. 151.

4 LYONS, J. Semantics. v. 02. Cambridge: Cambridge University Press, 1977.

5 VIDAL, M. V. E. Los enunciados interrogativos: aspectos semánticos y pragmáticos. In: BOSQUE, I.; DEMONTE, V. Gramática descriptiva de la lengua española: entre la oración y el discurso - morfología. vol. 03. España/Madrid: Espasa Calpe, 1999. 
Retomando alguns trabalhos desenvolvidos sobre esse tema, nomeadamente os trabalhos de Fontes ${ }^{6}$, sobre o uso de Interrogativas de Conteúdo em contexto de sala de aula, e de Fontes e Pezatti ${ }^{7}$, sobre questóes gerais a respeito das funçốes e das formas das Interrogativas de Conteúdo, nosso objetivo aqui é o de precisar os diferentes propósitos comunicativos a que se serve o uso das Interrogativas de Conteúdo para, assim, propor que se pense a natureza da interrogação a partir de uma tipologia que prevê três diferentes funçôes para as Interrogativas de Conteúdo.

É com base no modelo teórico-metodológico da Gramática Discursivo-Funcional (doravante GDF), conforme concebido por Hengeveld e Mackenzie (2008), ${ }^{8}$ que encontramos o principal critério a nos conduzir na caracterização das funçóes das Interrogativas de Conteúdo e na proposiçấo de uma tipologia tripartida para elas: a configuração do operador de identificabilidade atribuído ao constituinte interrogativo, que corresponde a um Subato Referencial no Nível Interpessoal. Partimos da hipótese de que os diferentes usos e funçōes das Interrogativas de Conteúdos, determinados pelas diferentes intençôes comunicativas e interacionais do Falante, refletem-se na configuração do operador de identificabilidade atribuído ao constituinte interrogativo.

Como material de análise, selecionamos dados orais e escritos do português brasileiro. Para os dados orais, utilizamos os inquéritos do Projeto NURC que compóem o Córpus mínimo do Projeto da Gramática do Português Falado. Para os dados escritos, selecionamos peças de teatro e cartas pessoais.

Este trabalho se divide da seguinte maneira: primeiramente, apresentamos o modelo da GDF e o tratamento dispensado por esse modelo à referenciação; num segundo momento, propomos uma tipologia para as Interrogativas de Conteúdo que leva em conta suas funçôes discursivas e interacionais; e, por fim, traçamos nossa noção de interrogaçáo a partir da tipologia proposta.

6 FONTES, M. G. Interrogativas de conteúdo em elocuçôes formais do português brasileiro. Guavira Letras, v. 12, p. 88-103, 2011.

7 FONTES, M. G.; PEZATTI, E. G. As interrogativas de conteúdo na história do português brasileiro: uma abordagem discursivo-funcional. São Paulo: Cultura Acadêmica, 2012.

8 HENGEVELD, K.; MACKENZIE, L. Functional Discourse Grammar: a typologicallybased theory of language structure. Oxford: Oxford University Press, 2008. 


\section{Fundamentação teórica}

\subsection{A Gramática Discursivo-Funcional}

A GDF aborda a linguagem enquanto um instrumento de interação verbal e, assim, captura as propriedades formais das unidades linguísticas e as descreve em termos da intenção comunicativa em que são produzidas. A figura 01 abaixo mostra a GDF como o Componente Gramatical de um modelo mais global de interação verbal que se liga a um Componente Conceitual, a um Componente Contextual e a um Componente de Saída.

Figura 01: A GDF como parte de uma teoria da interação verbal ${ }^{9}$

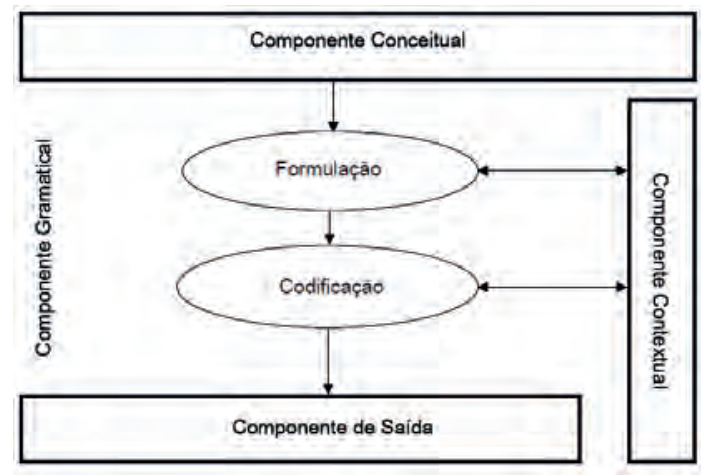

Partindo da idéia de que um modelo gramatical é mais eficiente à medida que reflete o processamento linguístico individual e de que, segundo alguns estudos psicolinguísticos, a produção linguística é um processo top-down, que começa com as intenções e termina com a articulação da expressão linguística, a implementação dinâmica da GDF reflete esse processo de produção linguística. Dessa forma, segundo o modelo da GDF, o Falante primeiro decide um propósito comunicativo, seleciona a informação mais adequada para alcançar seu propósito, codifica, então, esta informação gramaticalmente e fonologicamente, e, por fim, progride para a articulação.

Para a GDF, no nível pré-linguístico, ou seja, no Componente Conceitual, uma intenção comunicativa e sua representação mental são convertidas,

9 HENGEVELD, K.; MACKENZIE, J. L. Gramática Discursivo-Funcional. In: SOUZA, E. R. (org.). Funcionalismo linguístico: novas tendências teóricas. Trad. Marize Mattos Dall'Aglio-Hattnher. São Paulo: Contexto, 2012. p. 43-82. 
por meio da operação de Formulação, em representaçóes interpessoais e representacionais, que, transportadas para o nível morfossintático e fonológico por meio da operação de Codificação, recebem diferentes representaçôes.

Uma gramática orientada para o discurso necessita tanto do reconhecimento de vários níveis de análise como da aplicação de uma organização em camadas que se estendam ao nível do discurso. Além disso, Hengeveld e Mackenzie ${ }^{10}$ reconhecem a necessidade de uma gramática organizada a partir de quatro níveis: o Interpessoal, o Representacional, o Morfossintático e o Fonológico. Cada nível é concebido como um módulo separado e internamente organizado em camadas.

$\mathrm{Na}$ figura 02 a seguir, encontra-se um quadro no qual é demonstrada a organização geral da GDF. As elipses correspondem às operações (formulação ou codificação), os retângulos são os níveis de representação produzidos pelas operaçóes e os quadrados contêm os primitivos usados nas duas operaçóes citadas. Primitivos, grosso modo, são blocos construtores usados pelas operações para construir seus respectivos níveis de atuação.

Figura 02: Arquitetura geral da GDF ${ }^{11}$

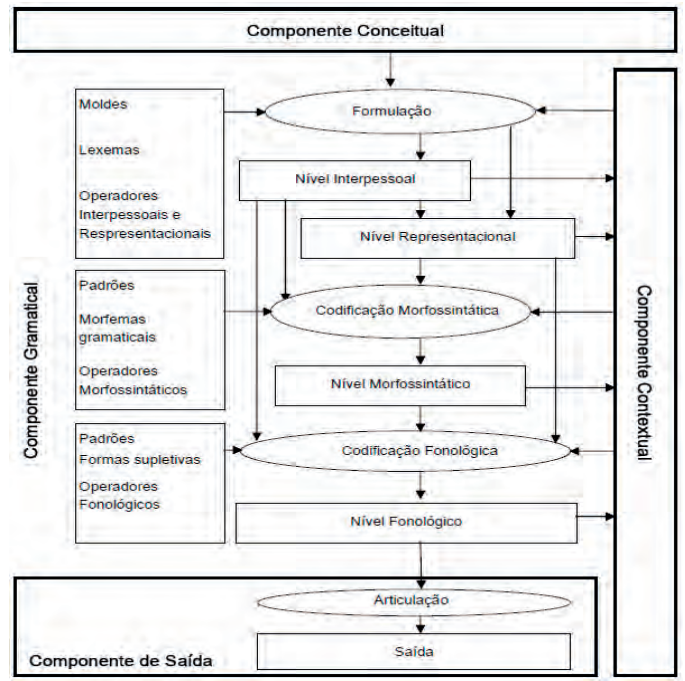

${ }^{10}$ HENGEVELD, K.; MACKENZIE, L. Functional Discourse Grammar: a typologicallybased theory of language structure. Oxford: Oxford University Press, 2008.

11 HENGEVELD, K.; MACKENZIE, L. Functional Discourse Grammar: a typologicallybased theory of language structure. Oxford: Oxford University Press, 2008. 
Cada um dos níveis distinguidos na GDF (Interpessoal, Representacional, Morfossintático e Fonológico) corresponde, respectivamente, aos níveis de análise linguística: pragmática, semântica, morfossintaxe e fonologia. Além disso, cada um se estrutura de um modo particular; entretanto, todos apresentam uma organização hierarquicamente ordenada em camadas.

No Nível Interpessoal, as unidades relevantes do comportamento comunicativo são formalizadas em termos de sua função comunicativa. Com base na formalização em (4), observa-se que a unidade de análise hierarquicamente mais alta nesse nível é o Movimento (M), que pode conter um ou mais Atos Discursivos (A). Um Ato Discursivo consiste em uma Ilocução (F), um ou mais Participantes do ato de fala $(\mathrm{P})$ e o Conteúdo Comunicado $(\mathrm{C})$ apresentado pelo falante. O Conteúdo Comunicado, por sua vez, pode conter um número variável de Subatos Atributivos (T) e Subatos Referenciais (R).

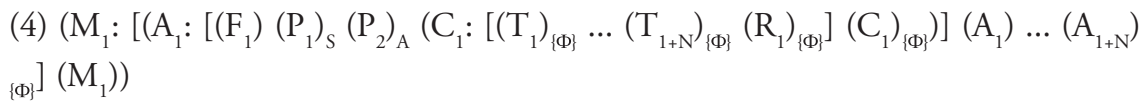

Já no Nível Representacional, descrevem-se as unidades linguísticas em termos de sua categoria semântica. Enquanto o Nível Interpessoal trata da evocação, o Representacional lida com a denotação. As camadas desse nível, disponíveis numa representação formalizada e hierarquicamente organizada em (5), são definidas em termos das categorias semânticas que elas designam: Conteúdos Proposicionais (p), as unidades mais altas do Nível Representacional, sấo construtos mentais, que podem conter um ou mais Episódios (ep), que são conjuntos de estados-de-coisas tematicamente coerentes, no sentido de que apresentam unidade ou continuidade de Tempo (t), Locação (l) e Indivíduos (x); já Estados-de-coisas (e) incluem eventos e estados que são caracterizados pela possibilidade de serem localizados no tempo e avaliados em termos de seu estatuto factual. Um estado-de-coisas se caracteriza por uma Propriedade Configuracional (f), que tem natureza composicional e contém uma combinação de unidades semânticas que não estão em relação hierárquica entre si, como Indivíduo (x), Locaçấo (l), Tempo (t), Modo (m), Razão (r) e Qualidade (q).

(5) $\left(\mathrm{p}_{1}:\left[\left(\mathrm{ep}_{1}:\left[\left(\mathrm{e}_{1}:\left[\left(\mathrm{f}_{1}\right):\left[\left(\mathrm{f}_{2}\right)^{\mathrm{n}}\left(\mathrm{x}_{1}\right)_{\Phi} \ldots\left(\mathrm{x}_{1+\mathrm{n}}\right)_{\Phi}\right]\left(\mathrm{f}_{1}\right)\right) \ldots\left(\mathrm{f}_{1+\mathrm{n}}\right)\left(\mathrm{e}_{1}\right)_{\Phi}\right]\right) \ldots\left(\mathrm{e}_{1+\mathrm{n}}\right)_{\{\Phi}\right]\left(\mathrm{ep}_{1}\right)\right) \ldots\left(\mathrm{ep}_{1+\mathrm{n}}\right)\right.$ $\left.\left.{ }_{[\Phi]}\right]\left(p_{1}\right)\right)$ 
Na operação de codificação, atuam os níveis Morfossintático e Fonológico. O Nível Morfossintático trata dos aspectos estruturais de uma unidade linguística. Juntamente com o Nível Fonológico, cuida da codificação das distinçôes interpessoais e representacionais. Em vista dessa função, muito do que ocorre no Nível Morfossintático é funcionalmente motivado: princípios de ordenação são motivados por iconicidade, integridade de domínio e pela preservação de relaçóes de escopo. Entretanto, deve-se levar em conta que esse nível tem seus próprios princípios de organização, que podem náo ser funcionalmente motivados. Conforme a representação em (6), a camada mais alta do Nível Morfossintático é a Expressão Linguística (EL), ou seja, qualquer conjunto de pelo menos uma unidade morfossintática; se houver mais de uma unidade dentro da EL, elas terão as mesmas propriedades morfossintáticas. As unidades que se combinam para formar a EL são: Oraçōes (Cl), Sintagmas (Xp) ou Palavras (Xw).

(6) $\left.\left(\mathrm{El}_{1}:\left[\mathrm{Cl}_{1}:\left[(\mathrm{Xw})\left(\mathrm{Xp}_{1}:\left[(\mathrm{Xw})\left(\mathrm{Xp}_{2}\right)\left(\mathrm{Cl}_{2}\right)\right]\left(\mathrm{Xp}_{1}\right)\right)\left(\mathrm{Cl}_{3}\right)\right]\left(\mathrm{Cl}_{1}\right)\right)\right]\left(\mathrm{El}_{1}\right)\right)$

O Nível Fonológico, por fim, é responsável pelos aspectos de codificação que não ocorrem no Nível Morfossintático. Ele recebe o input - alguns já na forma fonêmica - dos outros três níveis e provê o input para o Componente de Saída. Enquanto este último lida com questôes relacionadas a frequência, intensidade, duração, o Nível Fonológico - sendo gramatical - é digital, e contém representaçóes de fonemas que são baseadas em oposiçóes fonológicas binárias.

\subsection{A identificabilidade do referente segundo a Gramática Discursivo- -Funcional}

Segundo a GDF, a referenciação é uma atividade acional, situada no Nível Interpessoal, especificamente na camada dos Subatos; dessa forma, o ato de referenciação consiste numa ação pragmática e cooperativa entre o Falante e seu Ouvinte. Por ação pragmática, a GDF se refere à função primordial da interação, a de causar efeitos na informação pragmática do Ouvinte, e por cooperativa, refere-se à disposição de ambos os participantes em contribuírem entre si no alcance de seus objetivos comunicativos. 
Além de acional, a referenciação está envolvida numa ação mais global, a de evocação. Assim, um Falante evoca um Conteúdo Comunicado executando um número de Subatos Atributivos ou Referenciais. Enquanto os Subatos Atributivos envolvem a evocação de uma Propriedade, o Falante realiza um Subato Referencial para evocar uma Entidade. Segundo Hengeveld e Macken$\mathrm{zie}^{12}$, muitas línguas distinguem entre "construção do referente", quando o Falante deseja que o Ouvinte introduza um referente em seu modelo mental, e "identificação do referente", quando o Falante pede ao Ouvinte que identifique um referente disponível em sua (do Ouvinte) informação pragmática. Esta distinção reflete-se no operador de identificabilidade do Subato Referencial, conforme veiculada pelo Falante ${ }^{13}$. Tal ponto é bastante importante para nossa abordagem: a identificabilidade de um referente, na GDF, é tratada em termos da avaliação que o Falante faz de sua própria informação pragmática e de seu Ouvinte, quer dizer, é a perspectiva do Falante que se leva em conta na determinação da identificabilidade do referente.

A GDF distingue dois aspectos da identificabilidade: (i) o primeiro relaciona-se com a concepção do Falante a respeito da identificabilidade do Referente para o Ouvinte, o que gerará os operadores $\{+\mathrm{id},-\mathrm{id}\}$ para identificável e não-identificável; (ii) o segundo, por sua vez, relaciona-se à indicação dada pelo Falante a respeito da identificabilidade do referente para si próprio, o que se reflete nos operadores $\{+s,-s\}$ para específico e não-específico. A partir desses operadores, podemos prever quatro combinaçóes possíveis para um Subato Referencial: (i) $\{+\mathrm{id},+s\}$, (ii) $\{+\mathrm{id},-s\}$, (iii) $\{-\mathrm{id},+s\}$ e (iv) $\{-\mathrm{id},-s\}$.

A primeira combinação, $\{+\mathrm{id},+s\}$, aplica-se aos casos em que o referente, na pressuposição do Falante, é identificável para ambos os participantes (cf. (7)). Já a segunda, $\{+\mathrm{id},-s\}$, é aplicada aos casos em que o Falante assume o referente como identificável para o Ouvinte, porém não específico para ele próprio, o que está naturalmente associado à Ilocução Interrogativa (cf. (8)). A terceira combinação, por sua vez, $\{-\mathrm{id},+$ s $\}$, associa-se aos casos em que o

12 HENGEVELD, K.; MACKENZIE, L. Functional Discourse Grammar: a typologicallybased theory of language structure. Oxford: Oxford University Press, 2008.

13 A GDF, nos Níveis Interpessoal e Representacional, faz uma distinçáo entre operadores, funções e modificadores. Modificadores são estratégias lexicais de atualização de um Move, de um Ato, ou de outras camadas dos níveis Interpessoal e Representacional. Já funçôes e operadores são estratégias gramaticais, sendo que as funçôes são relacionais, e os operadores se aplicam a uma única unidade. 
Falante assume que ele conhece a identidade do referente, porém acredita que não ocorra o mesmo para seu Ouvinte (cf. (9)). E, por fim, a quarta combinação, $\{$-id, -s\}, corresponde aos casos em que o referente, para o Falante, não é identificável para nenhum dos participantes, nem para ele próprio, nem para seu Ouvinte (cf. (10)).

(7) $\mathbf{O}$ professor perguntou a todos os alunos da sala.

(8) Quem roubou minha bicicleta?

(9) Eu tenho alguns problemas com este texto.

(10) Eu estou procurando por alguém que possa me ajudar.

Os próprios autores da GDF, conforme se verifica acima, associam o operador $\{+$ id, $-s\}$ à Ilocuçáo Interrogativa. Dessa forma, conclui-se que o item interrogado, correspondente a um Subato Referencial no Nível Interpessoal, é sempre marcado como $\{+i d,-s\}$, ou seja, identificado para o Ouvinte, mas não especificado para o Falante. Assim, no Nível Interpessoal, o Subato Referencial (R) marcado $\{+\mathrm{id},-s\}$ será expresso por meio de um constituinte interrogativo e entonação apropriada, sob a influência da Ilocução Interrogativa. Entretanto, essa configuração $\{+i d,-s\}$ não é verificada para todos os exemplos de Interrogativas de Conteúdo encontradas e analisadas a partir de nossos dados. Com base em informaçóes contextuais, pode-se visualizar a presença de diferentes configuraçôes do operador de Identificabilidade sendo aplicadas ao Subato sob interrogação e é isso que se procura apresentar e defender na próxima seção.

\section{Uma tipologia tripartida para as Interrogativas de Conteúdo}

Conforme propóe Fontes, ${ }^{14}$ as Interrogativas de Conteúdo podem ser usadas em três diferentes contextos que se definem a partir da conjugaçáo de três fatores pragmáticos envolvidos na interaçáo verbal: (i) aquilo que o Falante

14 FONTES, M. G. Interrogativas de conteúdo em elocuções formais do português brasileiro. Guavira Letras, v. 12, p. 88-103, 2011. 
assume fazer parte de sua própria informação pragmática, (ii) aquilo que o Falante pressupóe estar ou não na informação pragmática de seu(s) Ouvinte(s) e (iii) a intenção comunicativa do Falante, em relação a seu(s) Ouvinte(s), com o uso da estrutura interrogativa.

Ao partir da configuração do operador de identificabilidade do Subato Referencial, este trabalho, retomando a proposta de Fontes e Pezatti, ${ }^{15}$ precisa esses três contextos interativos de uso das Interrogativos de Conteúdo, os quais corroboram a proposição, já estabelecida pelo autores citados, de uma tipologia tripartida para tais interrogativas: pergunta típica, pergunta retórica e pergunta meditativa.

Outras classificações, com base em diferentes perspectivas teóricas, já foram propostas para as estruturas interrogativas. Interessa-nos, aqui, duas perspectivas que dialogam bastante entre si: a de Araújo e Freitag ${ }^{16}$ e a de Oushiro e Nasser. ${ }^{17}$

Araújo e Freitag, numa visão funcionalista, classificam as perguntas em plenas, retóricas e semirretóricas. Oushiro e Nasser, por outro lado, com base na perspectiva da Análise da Conversação Etnometodológica e da Sociolinguística, consideram três tipos de perguntas: sinceras, retóricas e de estruturação do discurso. A proposta aqui apresentada, calcada nas consideraçóes de Fontes e de Fontes e Pezatti, dialoga em grande parte com as propostas de Araújo e Freitag e de Oushiro e Nasser, porém reestruturam-se as classificaçôes propostas pelas autoras, integrando sob o rótulo de perguntas retóricas as perguntas retórica e semirretórica, propostas por Araújo e Freitag, e as pergunta retórica e de estruturação do discurso, propostas por Oushiro e Nasser. Além disso, avança-se em relação a essas classificações ao propor um terceiro tipo não previsto pelas duas duplas de autoras, as perguntas meditativas. No quadro 01 a seguir, organizamos uma equivalência entre as propostas apresentadas.

15 FONTES, M. G.; PEZATTI, E. G. As interrogativas de conteúdo na história do português brasileiro: uma abordagem discursivo-funcional. São Paulo: Cultura Acadêmica, 2012.

16 ARAÚJO, A. S.; FREITAG, R. M. K. 'Quem pergunta quer resposta' - Perguntas como estratégia de interação na escrita. Via Litterae, v. 2, p. 321-335, 2010.

17 OUSHIRO, L; NASSER, J. A. O par pergunta-resposta em entrevistas sociolinguísticas. In: Congresso Internacional Linguagem e Interação II, 2010, São Leopoldo/RS. Anais... São Leopoldo: Casa Leiria, 2010. 
Quadro 01: Propostas de classificação para as interrogativas

\begin{tabular}{|ccc|}
\hline Oushiro e Nasser & Araújo e Freitag & Fontes e Pezatti \\
\hline pergunta sincera & pergunta plena & pergunta típica \\
\hline pergunta retórica & pergunta retórica & pergunta retórica \\
\cline { 1 - 2 } $\begin{array}{c}\text { pergunta de estruturaçáo } \\
\text { do discurso }\end{array}$ & pergunta semirretórica & \\
\hline & & pergunta meditativa \\
\hline
\end{tabular}

\subsection{As perguntas tipicas}

Perguntas típicas caracterizam-se por veicular um referente avaliado pelo Falante como identificável para o Ouvinte (+id) e como não específico (-s) para ele próprio. No Nível Interpessoal, dessa forma, as Interrogativas de Conteúdo com funçâo de pergunta típica apresentam o constituinte interrogativo, no caso um Subato Referencial, marcado pelo operador (+id, -s R).

As pergunta típicas são usadas em momentos da interação em que o Falante, assumindo seu desconhecimento perante uma informação, assinala seu desejo de que o Ouvinte, quem, para ele, detém esse conteúdo ausente, forneça a informação nova adequada. Esse tipo de pergunta, conforme se nota por sua definição, funciona como um pedido de informação: o Falante interage junto ao Ouvinte com o propósito de solicitar uma informaçáo nova que satisfaça seu desejo de conhecer o conteúdo interrogado, conforme se observa com os exemplos (11), (12) e (13):

(11) Examinei o Ne-|gocio; e achando que assim era, e que de nenhum modo | lhe servia o pôr-se na cauda de quanto regimento ou batalhão| se posesse em marcha, concordei com o Mont'alegre| em mandar saber - quem he ahi o Encarregado da Vacina? ... tem | familia a quem sustentar, e não tem outro modo de vida $\mid$ senáo esse?... pode ser nomeado para outra comissão, que | que dê pão, quando delle careça?... Responda-me, depois| de informar-se bem, sobre estes quesitos pelo Vapor In-|gles ou antes, se houver occasião.O Mont'alegre e o | Euzebio estão promptos á lhe servirem, e só lhes faltam | saber como. (carta do século XIX)18

18 CARNEIRO, Z. O. N. Cartas brasileiras (1809-1904): um estudo linguístico-filológico. Tese (Dourado em Linguística) - Instituto de Estudos da Linguagem, UNICAMP/Campinas, 2005. 
(12) Manuel João - Adeus, rapariga. Aonde está tua mãe? Aninha - Está lá dentro preparando a jacuba. (Teatro de Martins Pena do século XIX)

\section{(13) L2 onde é que elas estao?...}

L1 no Fernão Dias em Pinheiros (SP-D2-360)

Nesses exemplos, as interrogativas em negrito são solicitações do Falante para que seu Ouvinte preencha uma lacuna em sua informação pragmática com uma nova informação. Em (11), por exemplo, dado retirado de uma carta, a interrogativa em destaque evidencia uma lacuna de informação do remetente, cujo desejo está em saná-las junto a seu destinatário. Há duas frases que evidenciam o desconhecimento do escrevente e a busca pelas informaçóes ausentes: "concordei com o Mont'alegre| em mandar saber" e "Responda-me, depois| de informar-se bem, sobre estes quesitos". A primeira frase prefacia a sequência de perguntas dispostas, e a segunda fecha essa sequência de forma que o remetente deixa claro seu desconhecimento sobre o "Encarregado da Vacina” e seu desejo por obter informaçóes sobre ele.

As perguntas típicas correspondem ao que Oushiro e Nasser, por um lado, denominam de perguntas pragmaticamente sinceras e ao que, por outro lado, Araújo e Freitag denominam de perguntas plenas.

Para Oushiro e Nasser, essas perguntas são as mais próximas do protótipo do par pergunta-resposta e sua principal característica é a de criar no interlocutor a obrigaçáo de assumir o turno quando relevante e, assim, fornecer a segunda parte do par dialógico, que deve ser coerente com a pergunta feita. Dessa forma, as perguntas pragmaticamente sinceras passam o turno e buscam atualizar o fundo comum entre os participantes da interlocução, já que suas respostas podem trazer informaçóes novas e estabelecer novas crenças no inventário de conhecimento que os participantes compartilham. Essas propriedades são observadas, principalmente, nos exemplos (12) e (13), em que, tratando-se de situaçóes dialógicas (diálogo de uma peça de teatro em (12), e diálogo entre dois informantes em (13)), evidencia-se a iniciativa do Falante em buscar uma informação ausente para si junto a seu Ouvinte, que deve assumir o turno e responder coerentemente com a pergunta feita. Essa troca de turnos faz com que se atualize o fundo comum entre os participantes da interação. 
Por outro lado, Araújo e Freitag afirmam que as perguntas plenas são aquelas com que o Falante pede ao interlocutor uma resposta ou uma confirmação do que foi dito anteriormente. Há, por trás dessa visão, uma aproximação à natureza do par dialógico pergunta-resposta já que, conforme expóem as autoras, com esse tipo de pergunta, há aquele que pergunta e outro que responde.

\subsection{As perguntas retóricas}

Perguntas retóricas, por outro lado, caracterizam-se por veicular um referente avaliado pelo Falante como não identificável para o Ouvinte (-id), mas como específico $(+s)$ para ele próprio. No Nível Interpessoal, dessa forma, as Interrogativas de Conteúdo com função de pergunta retórica apresentam o constituinte interrogativo, no caso um Subato Referencial, marcado pelo operador (-id, +s R).

As perguntas retóricas são usadas em momentos da interação em que o Falante não necessariamente busca uma informação nova no conhecimento do seu Ouvinte, mas se utiliza da estrutura interrogativa como um mecanismo argumentativamente saliente de se transmitir uma informação nova ao $\mathrm{Ou}$ vinte, conforme demonstra o exemplo (14).

(14) Um afetuoso abraço para os teus, um beijinho para a Hilda, e para você minha santa que mandarei? aceita um beijo com toda a força de meu amor (carta do século XX)

Em (14), trecho de uma carta trocada entre namorados no início do século XX, o Falante, ao elaborar a interrogativa destacada, não pede uma informação nova a seu Ouvinte, mas, já detendo uma resposta, contida no Ato Declarativo posposto ao Ato Interrogativo, deseja salientar e chamar a atenção do Ouvinte para essa parte do texto, a que traz a informação nova e relevante para seu Ouvinte. Nesse caso, o Falante elabora uma pergunta sem esperar que o Ouvinte a responda, pois, ao deter a informação solicitada na pergunta, o Falante pressupóe o desconhecimento do Ouvinte acerca de tal informação e, assim, deseja adicioná-la à informação pragmática de seu interlocutor. 
Esse tipo de pergunta funciona como uma estratégia argumentativa, especificamente como um recurso de saliência, isto é, de marcação de relevo textual, conforme definido por Travaglia ${ }^{19}$. Segundo o autor, o relevo pode (i) manter todos os elementos do tópico discursivo em um mesmo plano, caso em que não há marcação de relevo, (ii) colocar determinados elementos dos textos em um plano mais alto, dando destaque especial em relação aos outros, caso em que há marcação de relevo positivo, e, por fim, (iii) colocar determinados elementos em um plano inferior, rebaixando-os em relação aos outros elementos, caso em que há marcação de relevo negativo.

As perguntas retóricas, portanto, constituem (i) mecanismos de marcação de relevo positivo, que contribuem com o desenvolvimento da argumentação ao destacar e salientar a informação nova trazida pelo Falante, e (ii) mecanismos de ênfase com que o Falante procura chamar a atenção de seu Destinatário.

Conforme se verifica nos exemplos em (15) e (16), a pergunta retórica, geralmente, vem seguida de um Ato Declarativo, que é, na verdade, uma resposta possível à interrogativa anteriormente expressa. Essa declaração está muito integrada à interrogação anterior de forma que, em dados orais, por exemplo, o Falante faz a pergunta e não abre espaço para que seu(s) Ouvinte(s) responda $(\mathrm{m})$ ou o interrompa $(\mathrm{m})$. Nota-se, então, que a Interrogativa de Conteúdo ali disposta estrutura o discurso numa estratégia de argumentação, de marcação de relevo positivo.

(15) MULLER - Está mais que evidente. Que mandava nas cidades? A CGT, Comando Geral dos Trabalhadores. Quem mandava no campo? As Ligas Camponesas. O Exército estava minado pelos sargentos e a Marinha pelos marinheiros. Não havia mais hierarquia, o terreno estava preparado para que os comunistas fizessem daqui uma nova Rússia. (Teatro de Dias Gomes do século XX)

(16) vocês agora eu acredito que já tenham tido... seis aulas de introduçao à ciência do direito... e também entre: cinco e oito aulas de teoria geral do

19 TRAVAGLIA, L. C. O relevo no processamento da informação. In: JUBRAN, C. C. S.; KOCH, I. G. V. (Orgs.). Gramática do português culto falado no Brasil: construçáo do texto falado. V. 1. Campinas: Editora da UNICAMP, 2006. p. 167-215. 
estado... portanto... já devem estar... mais ou menos por dentro até do linguajar:... da técnica jurídica... entao a perspectiva essa da dogmática jurídica como é que ela funciona? ela funciona dan:do uma interpretaçao... lógico-formal... da lei... e é isso que vocês vao aprender... essa técnica de interpretar... cada lei... num é? (REC-EF-337)

Em (15), exemplo retirado de uma peça de teatro, para as perguntas trazidas pela personagem Muller, ela mesma dá a resposta sem que permita uma intervenção de seu interlocutor, o que deixa claro a função argumentativa e focalizadora das perguntas retóricas. Já em (16), exemplo de uma elocução formal, especificamente de uma aula, o Falante, um professor, ao orientar seus Ouvintes, seus alunos, sobre o domínio referencial que tratará naquele tópico discursivo, não deseja somente trazer, como informação nova, o modo como ele trabalha ou atua no campo jurídico, mas, por meio do uso da pergunta retórica, ele enfatiza esse novo conteúdo trazido, destaca e salienta a importância dessa informação naquele contexto de forma a chamar a atenção de seus Ouvintes para ela. Com esse dado, podemos observar claramente que, ao fazer a pergunta, o Falante não dá espaço para que seus Ouvintes tomem o turno e respondam.

Já no exemplo (17) abaixo, retirado de uma peça de teatro, as duas perguntas trazidas pela personagem Faustino não são respondidas pela própria personagem Faustino, já que a resposta, dentro do contexto criado, fica evidente para o Ouvinte.

(17) FAUSTINO, entrando - Estava ali defronte na loja do barbeiro, esperando que teu pai saísse para poder ver-te, falar-te, amar-te, adorar-te, e... MARICOTA - Deveras!

FAUSTINO - Ainda duvidas? Para quem vivo eu, senão para ti? Quem está sempre presente na minha imaginação? Por quem faço eu todos os sacrifícios?

MARICOTA - Fale mais baixo, que a mana pode ouvir. (Teatro de Martins Pena do século XIX)

Mesmo não sendo seguida por um Ato Declarativo que funciona como uma resposta possível, esse tipo de interrogativa não deixa de funcionar como 
uma pergunta retórica uma vez que, permanecendo marcada pelo operador (-id, +s R), traz uma informação nova que fica subentendida.

As perguntas retóricas correspondem, na classificação de Oushiro e Nasser, às perguntas retóricas e de estruturação do discurso e, na de Araújo e Freitag, às perguntas retóricas e semirretóricas. As perguntas retóricas, para as autoras, são aquelas em que o Falante não espera uma resposta de seu Ouvinte já que, segundo Oushiro e Nasser, tal informação já faz parte do fundo comum entre os interlocutores e a sua resposta é óbvia, ou, segundo Araújo e Freitag, sua função é a de conduzir apropriadamente o Ouvinte em direção à argumentação do Falante. As perguntas retóricas defendidas pelas autoras acima correspondem, assim, às perguntas retóricas que não vêm acompanhadas de um Ato Declarativo. Por outro lado, as perguntas de estruturação do discurso e semirretóricas correspondem às perguntas retóricas que vêm acompanhadas de um Ato Declarativo. Segundo Oushiro e Nasser, essas perguntas, assim como as retóricas, não esperam uma resposta do interlocutor, mas esta não é óbvia e deve ser fornecida pelo próprio falante; já Araújo e Freitag afirmam que essas perguntas não aguardam uma resposta, uma vez que esta já foi dada pelo próprio Falante; sua função, assim como a das perguntas retóricas, é a de conduzir argumentativamente o Ouvinte. Fontes e Pezatti optam por não distinguir essas estruturas pelo fato de ambas terem o mesmo operador de identificabilidade, (-id, $+s$ R), e, também, como aponta Araújo e Freitag, por ambas terem a mesma funcionalidade textual, destacando e salientando elementos textuais numa estratégia de marcação de relevo positivo, e interativa, chamando a atenção do Ouvinte numa estratégia de ênfase.

\subsection{As perguntas meditativas}

Perguntas meditativas, por fim, caracterizam-se por veicular um referente avaliado pelo Falante como não identificável para o Ouvinte (-id) e não específico (-s) para ele próprio. No Nível Interpessoal, dessa forma, as Interrogativas de Conteúdo com função de pergunta meditativa apresentam o constituinte interrogativo, no caso um Subato Referencial, marcado pelo operador (-id, -s R).

As perguntas meditativas relacionam-se a contextos em que o Falante, desconhecendo uma dada informação, direciona-se ao Ouvinte, quem, para 
o Falante, também desconhece a informação sob interrogação. Ou melhor, o Falante assume que a resposta para a pergunta é desconhecida tanto para ele próprio como para o seu Ouvinte. Esses casos de interrogativas não mostram uma busca do Falante por informação e nem uma estratégia do Falante de realçar um argumento ou uma informação que deseja incutir no conhecimento de mundo do Ouvinte; são, na verdade, momentos de reflexão, de devaneio, de elocubração, em que o Falante expóe uma dúvida, um pensamento.

O exemplo (18) abaixo, retirado de uma carta do século XIX, é o que melhor representa o uso de uma pergunta meditativa:

\section{Post Scriptum}

No mesmo pacote de Cartas escrevi uma ao meu amigo nosso amigo vosso Tio [inint.] É esquisito! Nada eu perco [_] onde estará o pacote ? (carta do século XIX) ${ }^{20}$

Situando-se na parte final da carta, especificamente no Post Scriptum, porção em que o Falante destaca alguma informação que não era cabível na porção textual que compóe o desenvolvimento da carta, o Falante informa o Ouvinte a respeito de umas cartas que havia escrito e posto num pacote, entretanto uma delas se perdeu e, assim, ele se questiona onde estaria tal carta. É óbvio, pelo contexto, que o Falante não espera que seu Ouvinte responda à pergunta, ele apenas exterioriza sua dúvida, deixando ao Ouvinte apenas o papel de testemunha de seus pensamentos, de suas reflexóes.

Esse tipo de pergunta caracteriza claramente o que Lyons ${ }^{21}$ denomina de "expor uma pergunta". O autor, ao tratar das interrogativas como atos de fala, afirma que há uma diferença entre fazer uma pergunta (asking a question) e expor uma pergunta (posing a question). Quando se expóe uma pergunta, somente se exterioriza ou se expressa uma dúvida, para a qual, muitas vezes, não se sabe uma resposta ou não se espera que o Ouvinte a responda, ou melhor, geralmente, elas não são endereçadas a uma segunda pessoa. Por outro lado, quando se faz uma pergunta, expóe-se a questão e indica-se para o Ouvinte

20 CARNEIRO, Z. O. N. Cartas brasileiras (1809-1904): um estudo linguístico-filológico. Tese (Dourado em Linguística) - Instituto de Estudos da Linguagem, UNICAMP/Campinas, 2005.

21 LYONS, J. Semantics. v. 02. Cambridge: Cambridge University Press, 1977. 
que essa questão deve ser respondida, isto é, há claramente um direcionamento do ato de fala interrogativo para a segunda pessoa da interlocução.

Com o dado em (18), notamos o não-endereçamento da estrutura interrogativa ao interlocutor, o qual figura apenas como uma testemunha de uma dúvida, de hipótese, de uma reflexão do Falante. Portanto, as perguntas meditativas são estruturas interrogativas para as quais o Falante não tem uma resposta nem espera uma resposta de seu Ouvinte. Trata-se, dessa forma, de expressão de pensamentos, dúvidas e atitudes subjetivas do Falante.

\section{Considerações finais: sobre a natureza da interrogação...}

É comum, entre as abordagens que primam pelo estudo da língua em uso, a equiparação ou o uso indiferente entre os termos interrogativa e pergunta. Oushiro, ${ }^{22}$ tentando diferenciar tais termos, propóem que se entenda por "pergunta" expressóes que desempenham funçóes discursivas, enquanto o termo "interrogativa" se refere a estruturas sintáticas. A proposta deste trabalho está em compreender interrogação como um fenômeno linguístico presente nas mais variadas línguas, enquanto pergunta corresponde a funções discursivas que podem ser de três tipos.

Essas funções discursivas desempenhadas pelas estruturas interrogativas, no caso deste trabalho pelas Interrogativas de Conteúdo, estão relacionadas a três diferentes contextos interativos. $\mathrm{O}$ quadro 2 abaixo deixa claro esses três diferentes usos das Interrogativas de Conteúdo.

Uma primeira situação interativa de uso das Interrogativas de Conteúdo se dá quando o Falante, assumindo que uma determinada informação não está disponível para ele próprio, acredita que o Ouvinte possa ajudá-lo. A interrogativa funciona, assim, como um pedido de informação do Falante para o Ouvinte, o que se denomina, neste trabalho, de perguntas típicas.

Já num segundo contexto de uso, o Falante assume que a informação sob interrogação faz parte de sua informação pragmática; dessa forma, tem-se uma referência específica para o Falante, porém não disponível para seu Ouvinte. Esse tipo de pergunta funciona como uma maneira de ativar ou acrescentar

22 OUSHIRO, L. Uma análise variacionista para as Interrogativas-Q. Dissertação (Mestrado em Linguística). São Paulo, SP: Faculdade de Filosofia, Letras e Ciências Humanas, Universidade de São Paulo, 2011. 
um determinado conhecimento na informação pragmática do Ouvinte, destacando uma informação para que o Falante aja argumentativamente junto ao Ouvinte, o que se denomina, aqui, de perguntas retóricas.

Por fim, a informação sob interrogação pode estar ausente para ambos, Falante e Ouvinte. Esse tipo de pergunta funciona como uma tentativa de o Falante expor suas dúvidas e/ou inquietaçóes, colocando o Ouvinte no papel de testemunha, o que se denomina, aqui, de perguntas meditativas.

Quadro 02: Tipologia tripartida das Interrogativas de Conteúdo

\begin{tabular}{|c|c|c|}
\hline & $\begin{array}{l}\text { Identificabilidade do referen- } \\
\text { te interrogado }\end{array}$ & $\begin{array}{c}\text { Função comunicativa e } \\
\text { interacional }\end{array}$ \\
\hline Pergunta típica & $\begin{array}{l}\text { (+id, -s R): o Falante assume } \\
\text { seu desconhecimento em re- } \\
\text { lação a uma determinada in- } \\
\text { formaçáo e pressupóe que seu } \\
\text { Ouvinte tenha conhecimento } \\
\text { de tal informação. }\end{array}$ & $\begin{array}{l}\text { Pedido de informação: tenta- } \\
\text { tiva do Falante em sanar, jun- } \\
\text { to a seu Ouvinte, uma lacuna } \\
\text { presente em sua informação } \\
\text { pragmática. }\end{array}$ \\
\hline Pergunta retórica & $\begin{array}{l}\text { (-id, +s R) } \rightarrow \text { o Falante as- } \\
\text { sume a especificidade para } \\
\text { si mesmo da informaçáo sob } \\
\text { interrogação e pressupóe que } \\
\text { o seu Ouvinte não a conheça. }\end{array}$ & $\begin{array}{l}\text { Chamada de atenção: es- } \\
\text { tratégia argumentativa do } \\
\text { Falante para adicionar uma } \\
\text { nova informação à consci- } \\
\text { ência de seu Ouvinte, dando } \\
\text { destaque e saliência a essa in- } \\
\text { formação. }\end{array}$ \\
\hline Pergunta meditativa & $\begin{array}{l}(-\mathrm{id},-\mathrm{s}) \rightarrow \text { para o Falante, } \\
\text { nem ele próprio e nem seu } \\
\text { Ouvinte possuem conheci- } \\
\text { mento a respeito do que se } \\
\text { está interrogando. }\end{array}$ & $\begin{array}{l}\text { Exposição de dúvidas e pen- } \\
\text { samentos: o Falante coloca o } \\
\text { Ouvinte como testemunha } \\
\text { de seus pensamentos e deva- } \\
\text { neios. }\end{array}$ \\
\hline
\end{tabular}

A nossa proposta aqui é que se pense a natureza da interrogação a partir dessa tipologia tripartida de usos, isto é, a natureza discursiva de uma estrutura interrogativa se caracteriza por, essencialmente, cumprir três diferentes funções na interação: (i) uma função típica, de pedido de informação, no caso das perguntas típicas; (ii) uma função retórica, de natureza argumentativa e enfática, no caso das perguntas retóricas; e, por fim, (iii) uma função meditativa, de natureza elocubrativa, no caso das perguntas meditativas. 
O que há por trás desses três contextos de uso da interrogação é que, para pelo menos um dos participantes, a informação requerida não faz parte de sua informação pragmática. É assim que se define, neste trabalho, a interrogação: a ausência de uma informação no estado mental de pelo menos um dos participantes da interação verbal que provoque uma expressão verbal indiciária dessa ausência.

\title{
ABOUT THE NATURE OF INTERROGATION
}

\begin{abstract}
This paper analyzes the different communicative purposes which Content Interrogatives, usually called WhInterrogatives, are used for. Based on the principles of Functional Discourse Grammar, we propose to think the nature of interrogation from a tripartite typology: typical, rhetoric and meditative questions.
\end{abstract}

KEYWORDS: Interrogation; Referentiation; Discursive and interactive functions.

Recebido em: 21/01/2013

Aprovado em: 12/08/2013 